\title{
Avanços na captação de dados sobre a população indígena no Censo Demográfico 2010
}

\author{
Nilza de Oliveira Martins Pereira*
}

O objetivo desta nota de pesquisa é fornecer subsídios para uma discussão acerca dos desafios atuais de análise dos dados censitários no tocante aos indígenas, assim como apresentar algumas perspectivas futuras necessárias para o avanço na produção dessas informações. Também, se discorre sobre procedimentos específicos adotados na produção desses dados e se sistematizam algumas inovações metodológicas introduzidas no Censo Demográfico 2010.

Palavras-chave: Indígenas. Censos Demográficos. Produção de dados. Brasil.

\footnotetext{
* Instituto Brasileiro de Geografia e Estatística (IBGE), Rio de Janeiro-RJ, Brasil (Nilza.pereira@ibge.gov.br).
} 


\section{Introdução}

Tem havido uma importante ampliação na captação de dados sobre as populações indígenas nos censos conduzidos pelos institutos de estatística em diversos países da América Latina (CEPAL, 2014). Esse movimento, ao mesmo tempo que se vincula a questões sociopolíticas nacionais, no sentido de melhor conhecer as características sociodemográficas desse contingente específico, associa-se a perspectivas internacionais para dar mais visibilidade aos povos indígenas (CEPAL, 2014; PEYSER; CHACKIEL, 1999; SCHKOLNIK; DEL POPOLO, 2005).

A questão da coleta de dados acerca de indígenas nos recentes censos nacionais realizados no Brasil é bastante ilustrativa dessas tendências (IBGE, 2005, 2010, 2012). Na trajetória mais recente dos censos brasileiros, aquele realizado em 1991 marca a inclusão da categoria "indígena" no quesito cor/raça. No último quarto de século, no âmbito dos censos realizados pelo Instituto Brasileiro de Geografia e Estatística (IBGE) em 2000 e 2010, houve uma substancial ampliação do levantamento de dados sobre os indígenas. Em 2010, entre outros aspectos, foram incluídas perguntas a respeito de etnia, língua falada no domicílio e detalhamento sobre a localização geográfica das Terras Indígenas, que são critérios de identificação de população indígena nos censos nacionais de diversos países (IBGE, 2010, 2012).

\section{Base territorial e tecnologias de coleta de dados}

A integração entre as bases cartográficas do IBGE e as da Fundação Nacional do Índio (Funai) foi fundamental para a aplicabilidade do questionário do Censo 2010 nas Terras Indígenas (TI), mediante a coincidência dos limites dos setores censitários. Para definição da malha de setores censitários das TIs, a rede de agências e unidades estaduais do IBGE coordenadas pelas equipes técnicas da sede no Rio de Janeiro organizou, analisou e incorporou as informações provenientes da Funai (IBGE, 2012).

Para efeito de coleta das informações e análises dos resultados do Censo Demográfico 2010, o conjunto de TIs foi constituído por aquelas que estavam nas situações fundiárias de declarada, homologada, regularizada, ou em processo de aquisição como reserva indígena até a data de 31 de dezembro de 2010. Os setores censitários que compuseram o conjunto das Tls reconhecidas em qualquer uma das quatro situações citadas totalizaram 2.830, sendo a maioria $(87,7 \%)$ pertencente ao grupo das terras com situação fundiária regularizada.

Além do processo de aperfeiçoamento da base territorial, vale destacar a importância de inovações tecnológicas, em particular o uso do chamado dispositivo móvel de coleta (DMC) (IBGE, 2010). Esse equipamento viabilizou a substituição do questionário em papel pelo eletrônico, possibilitando, entre outros aspectos, a incorporação de bancos descritores com nomes de aproximadamente 500 etnias e de 300 línguas indígenas, para que 0 recenseador pudesse se orientar. Além da praticidade no processo de coleta, o uso do DMC 
contribuiu para a redução do tempo na divulgação dos resultados e o aumento da qualidade das informações, por meio da crítica no momento em que os dados eram coletados, bem como eliminou o trabalho do recenseador na seleção dos questionários da amostra, sendo o sorteio dos domicílios realizado de forma automática (IBGE, 2010).

\section{Quesitos específicos sobre os indígenas}

Para os residentes nas TIs, o questionário do Censo 2010 incluiu uma série de quesitos relacionados a características domiciliares e individuais, visando uma melhor captação das especificidades dos indígenas (IBGE, 2010; PEREIRA, 2012).

Para fins censitários, o domicílio é o local destinado à residência ou moradia, que se subdivide em duas espécies: particular (permanente e improvisado ocupado) e coletivo (IBGE 2010). Especificamente para os domicílios particulares permanentes ocupados, situados dentro das TIs, foram feitas algumas alterações no questionário:

- foi introduzida a categoria "oca ou maloca” para tipo de domicílio;

- no quesito "o material predominante das paredes externas", foi incluída a categoria "sem parede";

- na forma de abastecimento de água utilizada no domicílio, foram incluídas as categorias "poço ou nascente na aldeia" e "fora da aldeia".

Como as características domiciliares são investigadas somente para os particulares permanentes, é fundamental que a classificação quanto à sua espécie esteja correta, pois em TIs podem existir grandes domicílios com muitos moradores indígenas que poderiam ser confundidos com domicílios coletivos.

No tocante às características individuais, os quesitos relacionados a seguir foram investigados em ambos os questionários (básico e amostra) aplicados no Censo Demográfico 2010, com exceção daquele relativo ao tema nupcialidade, que foi aplicado somente no questionário da amostra (IBGE, 2010).

- “Você se considera indígena?", aplicado somente para os residentes em Tls que se declararam em categoria diferente de indígena no quesito cor/raça. Essa pergunta foi introduzida na investigação censitária porque, nas provas-piloto do Censo Demográfico 2010 realizadas nas TIs, detectou-se que um número considerável de indígenas deixou de se considerar como tal, classificando-se nas demais categorias de cor/raça, o que ocasiona perda de informações referentes à etnia e à língua falada.

- “Qual é a sua etnia ou povo a que pertence?", aplicado para as pessoas que se declararam indígenas no quesito cor/raça e, também, para os residentes em Terras Indígenas que se declararam em categoria diferente de indígena no quesito cor/ raça (ou seja, branca, preta, amarela ou parda), mas responderam afirmativamente à pergunta "Você se considera indígena?". 
- Para as línguas faladas, foram indagadas: “Fala língua indígena no domicílio?”, “Qual(is)?” e "Fala português no domicílio?”. Primeiramente era indagado se o indígena falava uma língua indígena e, em caso afirmativo, perguntava-se o nome da língua, podendo ser indicadas até duas línguas faladas.

- O quesito "tem registro de nascimento", para as crianças de até dez anos de idade, foi incluído pela primeira vez no Censo Demográfico 2010 e teve como uma das categorias investigadas o Registro Administrativo de Nascimento Indígena (Rani). Essa opção somente era disponibilizada para as pessoas que se declarassem ou se considerassem indígenas.

- No tema nupcialidade, aplicado apenas no questionário da amostra, especificamente no quesito "vive em companhia de cônjuge ou companheiro(a)", para cada mulher unida ou casada foi coletado o nome do cônjuge/companheiro. Tal procedimento possibilitou a identificação de poliginia, isto é, a união simultânea de um homem com mais de uma mulher (cônjuge/companheira) residentes em um mesmo domicílio. Visto que a poliginia está presente em sistemas de organização social de diversos povos indígenas no Brasil, a informação foi conservada na base de dados.

A aplicação dessas perguntas para a população indígena revelou resultados de um país até então desconhecido para muitos pesquisadores da temática. As análises já realizadas basearam-se nos tópicos específicos, anteriormente mencionados sobre os indígenas, que são comuns aos dois tipos de questionários utilizados para o levantamento no Censo Demográfico 2010 e que são denominados, por convenção, resultados do universo. Contudo, muito ainda necessita ser avaliado, principalmente o que se refere a um novo tópico, a chamada "demografia linguística", bem como aqueles temas que foram investigados no questionário da amostra, tais como fecundidade, mortalidade, migração, entre outros, que possuem disponibilidade de resultados somente para as pessoas que se declararam indígenas no quesito da cor/raça, pois a pergunta "Você se considera indígena?", que foi aplicada nas Terras Indígenas, tem sua representatividade estatística apenas para os resultados do universo.

\section{Cenários e perspectivas}

Aproximadamente uma década atrás, na introdução do livro Demografia dos povos indígenas no Brasil, Pagliaro et al. (2005, p. 11) afirmaram: "São ainda muito pouco conhecidas as mais diversas dimensões da dinâmica demográfica [...] dos povos indígenas no Brasil contemporâneo. Se essa assertiva se aplica plenamente ao conjunto dos povos indígenas, torna-se ainda mais contundente em face da diversidade dessas sociedades". Por um lado, tal cenário ainda se aplica; por outro, é inquestionável que foram dados importantes passos no sentido de reverter esse quadro. Como se pode depreender do detalhamento apresentado nas seções anteriores, comparado aos seus antecessores, é 
patente que o Censo de 2010 representou um significativo avanço no sentido de ampliar a captação de dados acerca dos indígenas no Brasil.

Ainda mais no caso brasileiro, por envolver a necessidade de cobertura de um espaço geográfico particularmente vasto, os censos nacionais constituem atividades extremamente complexas e de elevado custo. Como em qualquer outro censo nacional, um contínuo desafio dos levantamentos censitários realizados no país é o equilíbrio entre caracterizar o geral e o específico. Nesse sentido, por ocasião das atividades de planejamento de um censo nacional, é inevitável que as demandas de inclusão de questões a serem investigadas nas mais diversas áreas superem em muito as efetivas possibilidades de inclusão nos instrumentos de coleta.

No caso da população indígena no Brasil, é possível indicar que, de maneira geral, importantes demandas colocadas na fase de planejamento do Censo 2010 vieram a ser incorporadas nos questionários, tais como o levantamento de dados em todos os domicílios e não por amostra e a coleta de informações sobre etnia e língua falada pelos indígenas. Houve também ênfase quanto a uma adequação conceitual, isto é, que as variáveis investigadas no questionário da amostra fossem mais sensíveis para captar as características da população residente nas Tls. Outras não foram possíveis de implementar, como a participação de recenseadores indígenas nas Tls.

No âmbito desse breve texto, não é minimamente possível, e tampouco é o intuito, apresentar análises e interpretações a partir dos dados censitários relativos aos indígenas revelados pelos censos demográficos. Ao mesmo tempo que foram realizados substanciais esforços no sentido da coleta das informações, é fundamental que os dados sejam intensamente utilizados em investigações com vistas não somente a expandir os conhecimentos sobre as realidades sociodemográficas indígenas no país, mas também para uma avaliação crítica das categorias empregadas na captação. Há um crescente número de análises voltadas para os dados censitários sobre os indígenas, tanto realizadas no âmbito do IBGE (2012) como pela comunidade acadêmica. É sempre importante enfatizar que os dados dos censos e das demais pesquisas realizadas pelo IBGE são publicamente disponíveis e, especificamente para a população indígena, foram introduzidas informações no site do IBGE em sistemas específicos, ${ }^{1}$ com o objetivo de manter atualizados os usuários, em geral, e especialistas voltados para a temática indígena.

Vale salientar que a coleta das informações para os indígenas no Censo Demográfico 2010 foi semelhante aos não indígenas, não havendo nenhum procedimento comportamental para uma abordagem a um segmento populacional com certa especificidade. Foi preparada uma cartilha de conduta por sugestão de pesquisadores, visando uma melhor acessibilidade dos recenseadores nas aldeias indígenas, bem como alertar para alguns quesitos que careciam de maior atenção para sua obtenção, contudo, não houve

\footnotetext{
${ }_{1}^{1}$ Os aplicativos do IBGE, disponíveis de forma aberta ao público, que possuem informações agregadas sobre populações indígenas, principalmente por Terras Indígenas são: 〈http://indigenas.ibge.gov.br〉, 〈http://www.censo2010.ibge.gov.br/ terrasindigenas〉 e 〈http://www.ibge.gov.br/apps/atlas_nacional〉.
} 
treinamento específico para o recenseador que fosse para as Terras Indígenas. Como o processo seletivo para a contratação dos recenseadores não previa a contratação específica para indígenas, isso muito deve ter contribuído para o não entendimento de algumas respostas, principalmente, nos temas específicos (etnia e língua falada). De modo geral, os resultados referentes à declaração da língua indígena falada foram melhores do que aqueles sobre etnias indígenas, o que muito se deve ao melhor entendimento do quesito língua do que o da etnia, pelo próprio significado da palavra "etnia". Para o próximo censo demográfico (2020), recomenda-se que os recenseadores que forem atuar nas Terras Indígenas sejam indígenas e que durante o treinamento sejam feitas alertas quanto às especificidades dessa população.

Com os resultados proporcionados pelo Censo Demográfico 2010, existe a necessidade de estudos linguísticos e antropológicos mais aprofundados, pois algumas línguas declaradas podem ser variações de uma mesma língua, assim como algumas etnias também se constituem em subgrupos ou segmentos de uma mesma etnia. 0 dimensionamento do número de etnias e línguas declaradas pela população indígena do Brasil, segundo o Censo Demográfico 2010, surpreendeu quanto aos seus resultados e isso está associado à sua abrangência nacional, pois a maioria das pesquisas que estimavam o número de etnias e línguas indígenas excluía as áreas urbanas do país. Portanto, o Censo Demográfico 2010 veio preencher uma grande lacuna quanto à precariedade de informações nacionais para esse segmento populacional e desvendar um país até então desconhecido.

Para finalizar, cabe mencionar que na revisão da agenda da Conferência Internacional sobre População e Desenvolvimento - CIPD, em sua versão regional da América Latina, realizada em 2013 em Montevidéu, foi incluído um capítulo específico sobre populações indígenas, reconhecendo as especificidades deste segmento populacional (CAVENAGHI, 2014). Ainda, recomendações específicas para as populações indígenas foram propostas, dentre as quais está a promoção de medidas destinadas a reduzir disparidades étnico-raciais e assegurar o pleno exercício dos direitos individuais e coletivos desses grupos com igualdade de oportunidades, em especial no que se refere à devolução de terras e territórios ancestrais e ao acesso à saúde, nutrição e educação (FREITEZ, 2014). Assim, a realização de estudos dirigidos para a interpretação dos dados censitários existentes e a continuação das discussões acerca da melhoria quanto à sua captação nas pesquisas domiciliares muito contribuirão para maior visibilidade desses segmentos populacionais nos censos futuros.

\section{Referências}

CAVENAGHI, S. A dinâmica populacional e a agenda de população e desenvolvimento sustentável. In: WONG, L. R.; ALVES, J. E.; VIGNOLI, J. R.; TURRA, C. M. (Org.). Perspectivas de la agenda de población y desarrollo sostenible después de 2014. Rio de Janeiro: Alap Editora, 2014. p. 79-93.

CEPAL - Comissão Econômica para a América Latina e o Caribe. Los pueblos indígenas en América Latina: avances en el último decenio y retos pendientes para la garantía de sus derechos. Santiago: Cepal/Naciones Unidas, 2014. 
FREITEZ L. A. La agenda de población y desarrollo 20 años después de la CIPD: reflexiones desde la Asociación Latinoamericana de Población. In: WONG, L. R.; ALVES, J. E.; VIGNOLI, J. R.; TURRA, C. M. (Org.). Perspectivas de la agenda de población y desarrollo sostenible después de 2014. Rio de Janeiro: Alap Editora, 2014. p. 269-290.

IBGE - Instituto Brasileiro de Geografia e Estatística. Tendências demográficas: uma análise dos indígenas com base nos resultados da amostra dos Censos Demográficos 1991 e 2000. Rio de Janeiro: IBGE, 2005.

. Manual do recenseador. Censo 2010. CD 1.09. Rio de Janeiro: IBGE, 2010. Disponível em: 〈http://biblioteca.ibge.gov.br/visualizacao/instrumentos_de_coleta/doc2601.pdf〉.

. Características gerais dos indígenas no Censo Demográfico 2010 - resultados do Universo. Rio de Janeiro: IBGE, 2012.

PAGLIARO, H.; AZEVEDO, M. M.; SANTOS, R. V. Demografia dos povos indígenas no Brasil: um panorama crítico. In: PAGLIARO, H.; AZEVEDO, M. M.; SANTOS, R. V. (Org.). Demografia dos povos indígenas no Brasil. Rio de Janeiro: Editora Fiocruz/Associação Brasileira de Estudos Populacionais, 2005. p. 11-32.

PEREIRA, N. O. M.; SANTOS, R. V.; AZEVEDO, M. M. Perfil demográfico e socioeconômico das pessoas que se autodeclararam indígenas nos Censos Demográficos de 1991 e 2000. In: PAGLIARO, H.; AZEVEDO, M. M.; SANTOS, R. V. (Org.). Demografia dos povos indígenas no Brasil. Rio de Janeiro: Editora Fiocruz/Associação Brasileira de Estudos Populacionais, 2005. p. 155-166.

PEREIRA, N. O. M. Inovações na pesquisa do indígena do Censo Demográfico 2010 do Brasil. In: V CONGRESSO DA ASSOCIAÇÃO LATINOAMERICANA DE POPULAÇÃO. Anais... Montevideo: Alap, 2012.

PEYSER, A.; CHACKIEL, J. La identificación de poblaciones indígenas en los censos de América Latina. In: CEPAL/NACIONES UNIDAS (Org.). América Latina: aspectos conceptuales de los censos del 2000. Santiago: Cepal/Naciones Unidas, 1999. p. 353-363.

SCHKOLNIK, S.; DEL POPOLO, F. Los censos y los pueblos indígenas en América Latina: una metodología regional. Notas de Población, n. 79, p. 101-132, 2005.

\section{Sobre a autora}

Nilza de Oliveira Martins Pereira é estatística e doutora em Saúde Pública pela Escola Nacional de Saúde Pública Sergio Arouca, da Fundação Osvaldo Cruz (Ensp/Fiocruz). Pesquisadora do Instituto Brasileiro de Geografia e Estatística (IBGE)

\section{Endereço para correspondência}

Instituto Brasileiro de Geografia e Estatística

Avenida República do Chile, $7^{\circ}$ andar

20031-170 - Rio de Janeiro-RJ, Brasil 


\begin{abstract}
Advances in data production about indigenous population in the Demographic Census of 2010

The purpose of this research note is to provide inputs to a discussion of the current challenges on the analysis of census data regarding indigenous peoples, as well as to present some future perspectives needed to advance in the production of such information. Also, it discusses about specific procedures adopted in the data production and systematize some methodological innovations introduced in the Brazilian Demographic Census of 2010.
\end{abstract}

Keywords: Indigenous. Demographic Census. Data production. Brazil.

\title{
Resumen
}

Los avances en la producción de datos sobre la población indígena en el Censo Demográfico de 2010

El objetivo de esta nota de investigación es proporcionar insumos para el debate sobre los retos actuales en el análisis de los datos del censo con respecto a los pueblos indígenas, así como presentar algunas perspectivas futuras necesarias para avanzar en la producción de dicha información. Además, se discute procedimientos específicos adoptados en la producción de estos datos y se sistematiza algunas innovaciones metodológicas introducidas en el Censo Demográfico de 2010 de Brasil.

Palabras clave: Indígenas. Censos Demográficos. Produción de datos. Brasil.

Recebido para publicação em 25/11/2015

Recomendado para publicação em 17/06/2016

Aceito para publicação em 15/09/2016 